\title{
EXHIBITION
}

\section{A protein ghost etched in glass}

\author{
Marta Paterlini \\ The starting point of the touring \\ exhibition Design4Science, \\ now running at the Nobel \\ Museum in Stockholm, was \\ the pioneering Laboratory of \\ Molecular Biology in Cambridge, \\ UK - the birthplace of protein \\ crystallography. Max Perutz, who \\ was chairman of the lab when it \\ was founded in 1962, encouraged \\ photographers and designers to \\ be part of the scientific team from \\ the start. \\ Wandering around the well- \\ known protein and virus models \\ that resulted, one much more \\ recent piece stands out: a dizzying \\ ghost of a protein molecule
}

mounted in a block of glass. Colin Rennie, a young artist from Sunderland, UK, took inspiration from ATP synthase, the molecule that rotates to produce adenosine triphosphate, the universal currency of biological energy. Rennie used a powerful water-jet cutter to recreate the threedimensional structure of the molecule in a 780-kilogram cube of $\mathbf{3 0}$ glass layers measuring 1 metre across.

Rennie's vibrant artwork captures the spatial and temporal fixity of protein crystallography and the sense of motion of this particular molecule. The transparent glass embodies the

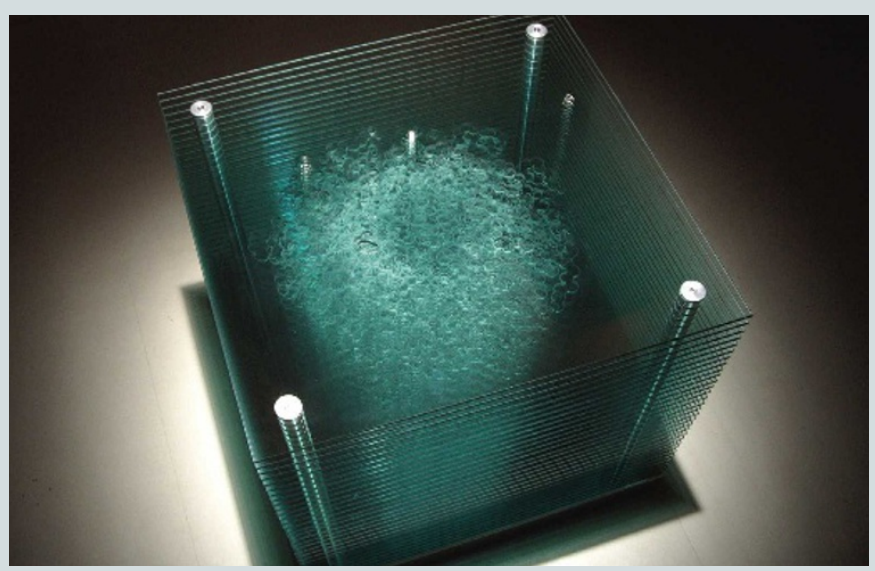

tension between the seen and the unseen that is intrinsic to our perception of the molecular world. At the same time, it mimics the protein crystals that give scientists their atomic models.

As the renowned scientific artist Irving Geis once said: "We can only say 'it's something like that' - and only create a visual metaphor." Marta Paterlini is a writer based in Stockholm, Sweden.

Design4Science runs until 31 August at the Nobel Museum, Stockholm (www.nobelmuseum.se).

\section{Census of cyberspace censoring}

\section{Access Denied}

edited by Ronald Deibert, John Palfrey, Rafal Rohozinski and Jonathan Zittrain MIT Press: 2008.320 pp. $\$ 20.00, £ 12.95$

\section{Bruce Schneier}

In 1993, Internet pioneer John Gilmore said "the net interprets censorship as damage and routes around it", and we believed him. In 1996, cyberlibertarian John Perry Barlow issued his 'Declaration of the Independence of Cyberspace' at the World Economic Forum at Davos, Switzerland, and online. He told governments: "You have no moral right to rule us, nor do you possess any methods of enforcement that we have true reason to fear."

At the time, many shared Barlow's sentiments. The Internet empowered people. It gave them access to information and couldn't be stopped, blocked or filtered. Give someone access to the Internet, and they have access to everything. Governments that relied on censorship to control their citizens were doomed.

Today, things are very different. Internet censorship is flourishing. Organizations selectively block employees' access to the Internet. At least 26 countries - mainly in the Middle East, North Africa, Asia, the Pacific and the former Soviet Union - selectively block their citizens' Internet access. Even more countries legislate to control what can and cannot be said, downloaded or linked to. "You have no sovereignty where we gather," said Barlow. Oh yes we do, the governments of the world have replied.

Access Denied is a survey of the practice of Internet filtering, and a sourcebook of details about the countries that engage in the practice. It is written by researchers of the OpenNet
Initiative (ONI; www.opennet.net), an organization that is dedicated to documenting global Internet filtering around the world.

The first half of the book comprises essays written by ONI researchers on the politics, practice, technology, legality and social effects of Internet filtering. There are three basic rationales for Internet censorship: politics and power; social norms, morals and religion; and security concerns.

Some countries, such as India, filter only a few sites; others, such as Iran, extensively filter the Internet. Saudi Arabia tries to block all

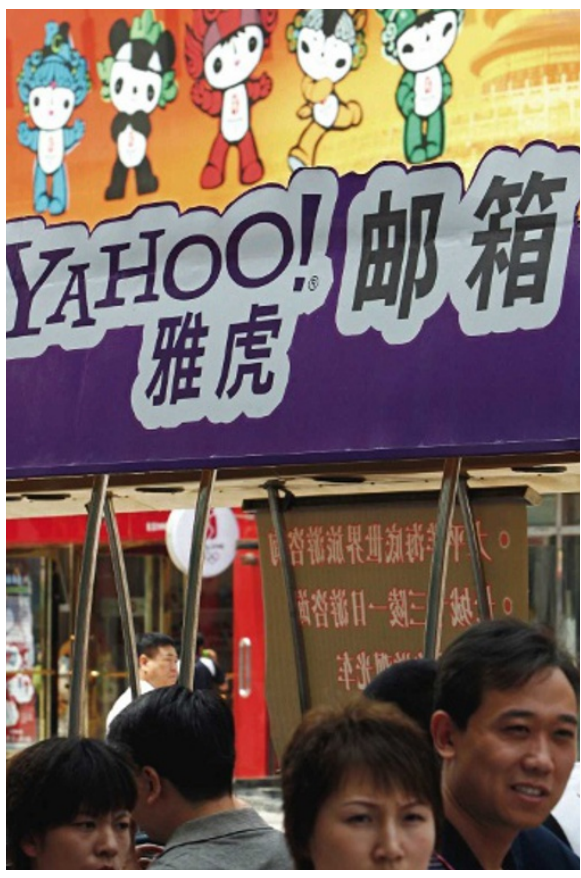

China restricts Internet access by keyword. pornography (social norms and morals). Syria blocks everything from the Israeli domain '.il' (politics and power). Some countries filter only at certain times. During the 2006 elections in Belarus, for example, the website of the main opposition candidate disappeared from the Internet.

The effectiveness of Internet filtering is mixed; it depends on the tools used and the granularity of filtering. It is much easier to block particular URLs or entire domains than it is to block information on a particular topic. Some countries block specific sites or URLs based on some predefined list but new URLs with similar content appear all the time. Other countries - notably China - try to filter on the basis of keywords in the actual web pages. A halfway measure is to filter on the basis of URL keywords: names of dissidents or political parties, or sexual words.

Much of the technology has other applications. Software for filtering is a legitimate product category, purchased by schools to limit access by children to objectionable material and by corporations trying to prevent their employees from being distracted at work. One chapter discusses the ethical implications of companies selling products, services and technologies that enable Internet censorship.

Some censorship is legal, not technical. Countries have laws against publishing certain content, registration requirements that prevent anonymous Internet use, liability laws that force Internet service providers to filter themselves, or surveillance. Egypt does not engage in technical Internet filtering; instead, its laws discourage the publishing and reading of certain content - it has even jailed people for their online activities. 


\section{EXHIBITION \\ Beauty meets utility at MoMA}

Josie Glausiusz

A pudgy, pink, pig-like creature, lacking a head but sprouting a tuft of unruly hair, sits in a corner of the Museum of Modern Art (MoMA) in New York. Epidermits, a stubbylegged quadruped, was purportedly spawned from a skin-and-hair-cell culture grown from a human cheek swab, and is fed on a 'sustain solution' infused through its tail. If carefully nurtured, it could be expected to live as long as "a large dog or a donated kidney".

So says designer Stuart Karten, who claims that his ten-centimetrelong, yet-to-be-realized organism could be a pet of the future. Our ability to incorporate such fantastic ideas into everyday life is the subject of MoMA's new exhibition, Design and the Elastic Mind, which explores the myriad ways in which our minds rapidly adapt to technological changes. This marvellous hodge-podge of exhibits comprises 200 creations that range in size from nano-scale smiley-faces stitched together from viral DNA, to an imposing five-metre-tall sculpture by Chuck Hoberman called Emergent Surface - a screen of twisting and unfolding slatted steel panels that move in response to changes in light. Practical gadgets sit beside whimsical pieces such as the 'smell augmentation' plugs that artist Susana Soares invites us to stuff up our nostrils.

At their best, these devices marry beauty and utility. Martin and Erik

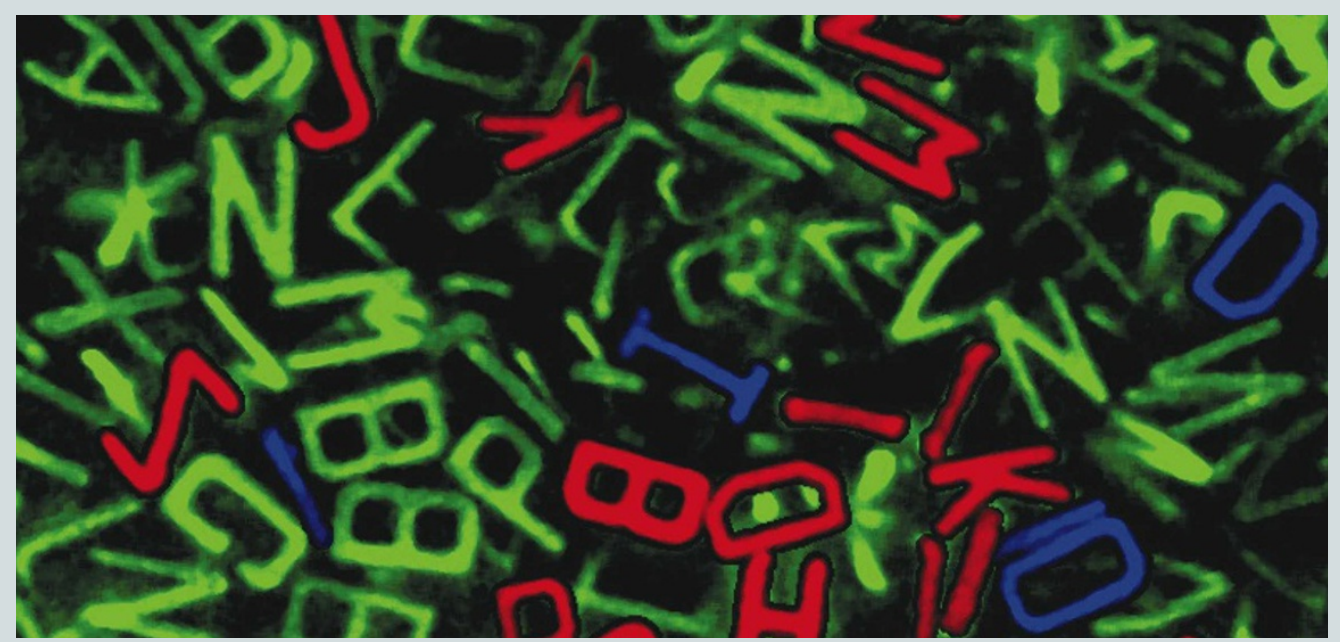

'Colloidal Alphabet Soup': these 7-micrometre-long polymer letters could be used to label individual cells.

Demaine, a father-and-son team from the Massachusetts Institute of Technology (MIT), created Computational Origami - delicately folded, interlocking paper loops that demonstrate the use of computer-aided design to squeeze large objects into small spaces. A similar concept underlies Robert Lang's origami models of the Fresnel lens for the Eyeglass Space Telescope (a mothballed project of the Lawrence Livermore National Laboratory in California). The lens, if realized, could have been scrunched up, launched and then expanded in space to a diameter of 100 metres - roughly the length of an American football field. Elegance and expediency also underlie the Sonumbra sculpture created by Rachel Wingfield and Mathias Gmachl, a tree-like 'sonic shade of light' that transforms peoples' movements via software into serene sounds that are reminiscent of those produced with a Tibetan singing bowl. Solar cells embedded in the green, umbrellalike shade of Sonumbra harvest energy during the day to power the lights at night.

Some of the most compelling items in Design and the Elastic Mind are simple, yet could prove essential to populations that lack basic equipment. Bernhard Weigl's credit-card-sized 'Lab on a Card' can diagnose an intestinal infection from a small faecal sample in 20 minutes. Emili Padrós's ‘Non-Stop Shoes' use the energy generated from walking and stair-climbing to run lamps and radios. Similarly, the green-keyed XO laptop computer designed by MIT's Media Lab is "lighter than a lunchbox" and has a battery that can be recharged by pulling a cord wrapped like a yo-yo. It is being distributed to schools in Uruguay, Afghanistan, Cambodia and Mexico, among others, as part of the 'One Laptop Per Child' project, a non-profit programme to deliver laptops to the world's poorest children in remote areas.
What makes the exhibition so electrifying is the imagination that drives these innovations. A charming example is a series of drawings inspired by artist Alan Outten, who challenged British primary-school children to design the future. Their inventions included 'Super-Human Mermaid', a genetically engineered human with the genes, gills and tails of a fish "in case the world floods due to pollution", and 'The Apple Phone', a tree with man-made seeds that "use nature as their energy source" to grow apple-like telephones, "so if you are having a private conversation, you just eat the apple". To quote Outten, I left the exhibition "with a sense that creativity and design are safe in the hands of the next generation". Josie Glausiusz is a journalist based in New York.

Design and the Elastic Mind runs at the Museum of Modern Art, New York, until 12 May (www.moma.org).
The second half of Access Denied consists of detailed descriptions of Internet use, regulations and censorship in eight regions of the world, and in each of 40 different countries. The ONI found evidence of censorship in 26 of those 40 . For the other 14 countries, it summarizes the legal and regulatory framework surrounding Internet use, and tests the results that indicated no censorship. This leads to 200 pages of rather dry reading, but it is vitally important to have this information welldocumented and easily accessible. The book's data are from 2006, but the authors promise frequent updates on the ONI website.

No set of Internet censorship measures is perfect. It is often easy to find the same information on uncensored URLs, and relatively easy to get around the filtering mechanisms and to view prohibited web pages if you know what you're doing. But most people don't have the computer skills to bypass controls, and in a country where doing so is punishable by jail - or worse - few take the risk. So even porous and ineffective attempts at censorship can become very effective socially and politically.

In 1996, Barlow said: "You are trying to ward off the virus of liberty by erecting guard posts at the frontiers of cyberspace. These may keep out the contagion for some time, but they will not work in a world that will soon be blanketed in bit-bearing media."

Brave words, but premature. Certainly, there is much more information available to many more people today than there was in
1996. But the Internet is made up of physical computers and connections that exist within national boundaries. Today's Internet still has borders and, increasingly, countries want to control what passes through them. In documenting this control, the ONI has performed an invaluable service.

Bruce Schneier is chief security technology officer for BT Counterpane, Santa Clara, California. He is author of Beyond Fear: Thinking Sensibly About Security in an Uncertain World.

\section{Correction}

Ken Arnold's review of The Anatomist by Bill Hayes (Nature 451, 247; 2008) incorrectly said that the mother's blood enters the fetal heart through a hole. In fact, this hole lets blood move from the right to the left atrium in utero and is sealed after birth. 